University of Wollongong

Research Online

Faculty of Science - Papers (Archive) Faculty of Science, Medicine and Health

May 1999

\title{
Thermoluminescence evidence for the deposition of coastal sediments by tsunami wave action
}

D. M. Price

University of Wollongong, dprice@uow.edu.au

Edward A. Bryant

University of Wollongong, ebryant@uow.edu.au

R. W. Young

Follow this and additional works at: https://ro.uow.edu.au/scipapers

Part of the Life Sciences Commons, Physical Sciences and Mathematics Commons, and the Social and Behavioral Sciences Commons

\section{Recommended Citation}

Price, D. M.; Bryant, Edward A.; and Young, R. W.: Thermoluminescence evidence for the deposition of coastal sediments by tsunami wave action 1999.

https://ro.uow.edu.au/scipapers/122

Research Online is the open access institutional repository for the University of Wollongong. For further information contact the UOW Library: research-pubs@uow.edu.au 


\title{
Thermoluminescence evidence for the deposition of coastal sediments by tsunami wave action
}

\author{
Abstract \\ Changes in our coastline take on various forms and are the product of differing wave and aeolian \\ processes. Of all these processes tsunami action surely represents the most rapid and violent agent \\ wreaking devastation not only along the immediate shoreline but also extending many kilometres inland. \\ Until now the main line of evidence supporting the deposition of sediments by this means has lain in the \\ careful examination of the sedimentological record. This process is painstaking, costly and time \\ consuming and then not necessarily conclusive. Thermoluminescence may offer an alternative line of \\ evidence which may be taken as either confirmatory or, on occasions, as an independent method of \\ establishing the depositional means of a sedimentary deposit.

\section{Keywords} \\ thermoluminescence dating, tsunami, Australia, Scotland, Storegga slide

\section{Disciplines} \\ Life Sciences | Physical Sciences and Mathematics | Social and Behavioral Sciences

\section{Publication Details} \\ This article was originally published as Price, DM , Bryant, EA, Young, RW, Thermoluminescence evidence \\ for the deposition of coastal sediments by tsunami wave action, Quaternary International 56(1), 1999, \\ 123-128. Original article available here.
}




\title{
Thermoluminescence evidence for the deposition of coastal sediments by tsunami wave action
}

\author{
David M. Price*, Edward A. Bryant, Robert W. Young \\ School of Geosciences, University of Wollongong, Northields Avenue, Wollongong. NSW 2522, Austratia
}

\begin{abstract}
Changes in our coastline take on various forms and are the product of differing wave and aeolian processes. Of all these processes tsunami action surely represents the most rapid and violent agent wreaking devastation not only along the immediate shoreline but also extending many kilometres inland. Until now the main line of evidence supporting the deposition of sediments by this means has lain in the careful examination of the sedimentological record. This process is painstaking, costly and time consuming and then not necessarily conclusive. Thermoluminescence may offer an alternative line of evidence which may be taken as either confirmatory or, on occasions, as an independent method of establishing the depositional means of a sedimentary deposit. C 1999 INQUA/Elsevier Science Ltd. All rights reserved.
\end{abstract}

\section{Introduction}

Sedimentary thermoluminescence (TL) dating is dependent upon the resetting of the previously acquired signal prior to deposition. This requires a considerable period of exposure to sunlight. Whilst this may well occur in the case of aeolian and normal water borne sediments there is very little time for this process to have taken place in the case of tsunami deposited sands. There is also the possibility that such events may take place overnight with no solar exposure. Whilst TL cannot yield any evidence in the latter situation it may well do so in the case of events which take place during daylight where partial solar exposure/resetting may have taken place.

Thermoluminescence dating is an electron capture method of analysis and the resetting process requires that the vast majority of trapped electrons are returned to their ground states during the transport phase of deposition. Electrons are trapped at various energy levels and in general the deeper the electrons are the greater the energy/solar exposure required to release them. Thus partial exposure such as might occur during a day time tsunami event may be sufficient to release electrons

*Corresponding author: E-mail: david price@uow.edu.au. trapped at the lower electron trap levels but insufficient to release those stored at higher energies. Heating to $500^{\circ} \mathrm{C}$ in the laboratory is sufficient to release all of the remaining electrons which give rise to a TL spectrum. If this is compared with a spectrum recently induced in the laboratory their differences indicate partial exposure of the sediment prior to deposition such as that associated with a tsunami event. Additionally where very little solar exposure has taken place, seemingly older sediment may be deposited directly onto younger deposits thus producing an apparent age reversal and offering a direct line of evidence that the depositional process has been of a violent and sudden nature. Evidence is presented here from the New South Wales south coast in support of this hypothesis where tsunamis have been identified as having a major impact upon the Late Quaternary coastal evolution of this region (Young et al., 1995; Bryant et al., 1996). The sedimentological make up of each of the examples presented is suggestive of extremely rapid deposition beyond the means of the most severe storm events recorded.

With the exception of pumice sample W1402 all samples have been analysed by means of the combined additive and regenerative technique (Readhead, 1984) using the 90-125 micrometre quartz grain fraction. Sample W1402 has been analysed using the 1-8 micrometre fine grain polymineral additive method (Aitken, 1995). 


\section{Study sites}

\section{Shoalhaven Deltaic Plain}

Features suggestive of incomplete TL minimisation are exhibited by one of the two samples taken from a site on the deltaic plain of the Shoalhaven River at Bolong near Nowra (Fig. 1). These are discussed by Young et al., (1996). Samples were taken $50 \mathrm{~cm}$ either side of an unconformity. The sample from beneath the unconformity displays a single temperature plateau characteristic extending between $300^{\circ} \mathrm{C}$ and $500^{\circ} \mathrm{C}$ (Fig. 2a) suggestive of substantial solar exposure prior to deposition. TL analysis of this sample yielded an age of $>106 \mathrm{ka}$ (W1907). The sample removed from $50 \mathrm{~cm}$ above the unconformity exhibits a stepped TL temperature plateau characteristic of incomplete TL minimisation before deposition. The two plateau regions extend between $275^{\circ} \mathrm{C}$ and $350^{\circ} \mathrm{C}$ and $375^{\circ} \mathrm{C}$ and $500^{\circ} \mathrm{C}$ (Fig. 2a). Subsequent analysis at two temperatures, $325^{\circ} \mathrm{C}$ and $375^{\circ} \mathrm{C}$, yielded an age of $15.5 \pm 1.5 \mathrm{ka}$ (W1908a) at the less stable, lower temperature and $26.6 \pm 3.2 \mathrm{ka}$ (W1908b) at the more stable higher temperature. The authors can find no reason to suggest that there has been a long period of erosion in the area following the Last Interglacial. They conclude therefore that the cause of such stripping is more likely to have taken place as the result of a sudden violent event such as a tsunami wave train. This was followed by the deposition of sand which had received insufficient solar exposure to remove all of the stored TL energy such as might well be entrained at the time of such an event.

A further piece of supportive evidence that such an event has taken place may be found in the examination of the second-glow TL curves recorded from the two samples. These are in fact distinctly different (Fig. 2b) which suggests that the two sedimentary units are not only of vastly differing age but are also of different origin (Price, 1994). It would seem therefore that the uppermost sand unit has been transported from a different region from
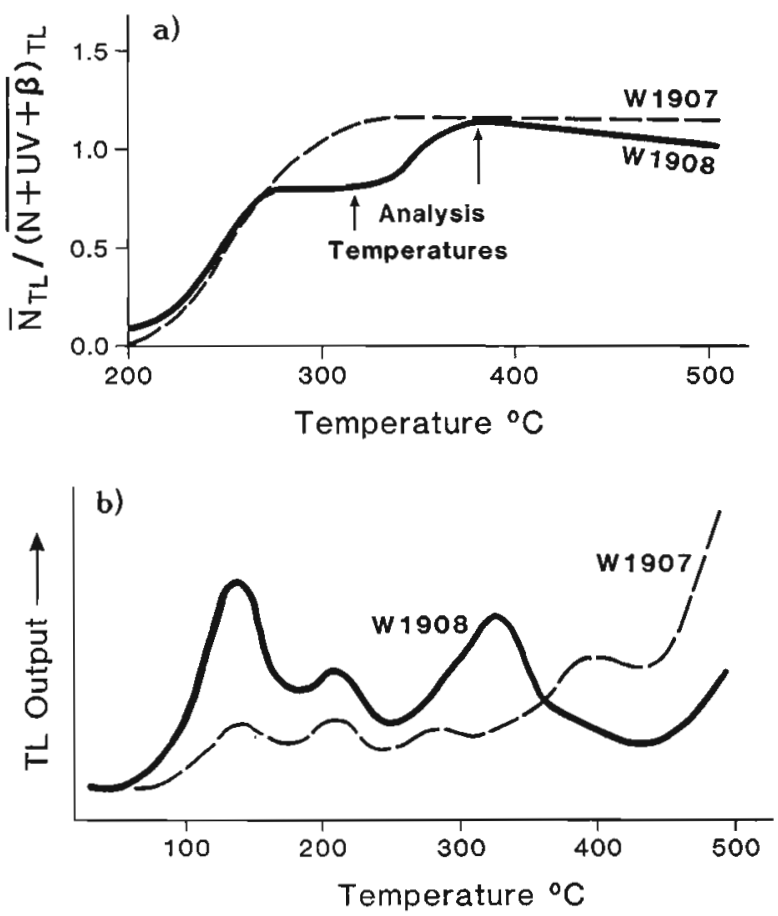

Fig. 2. Shoalhaven Delta. (a) Curves showing the ratio of natural TL $(\mathrm{N})_{\mathrm{TL}}$ divided by laboratory induced TL $(\mathrm{N}+\mathrm{UV}+\mathrm{B})_{\mathrm{TL}}$ with temperature. W1907, from beneath the unconformity, displays a single plateau (dotted line) whereas W1908, from above the unconformity, exhibits a stepped plateau characteristic (solid line) suggesting incomplete TL minimisation prior to deposition. (b) Second TL glowcurves demonstrating the characteristic difference betwen the 90-125 micrometre quartz grains extracted from above (W1908) and below (W1907) the unconformity at Bolong. This demonstrates the change in provenance of the sedimentary supply surce.

that of the lower unit. Furthermore the combined evidence suggests that the depositional processes associated with the two sedimentary units were significantly different.

Whether or not the TL age determined from the upper unit represents the suggested tsunami event is a matter of conjecture. In such a situation this determination could

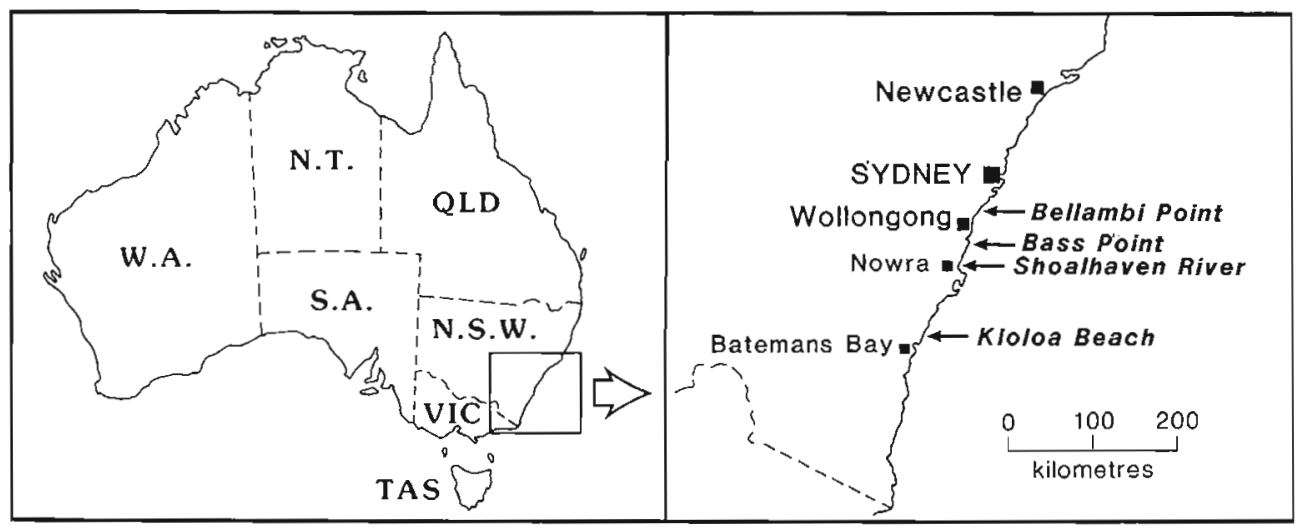

Fig. 1. Location map of New South Wales south coast showing location of anomalous tsunami deposits. 
well be expected to represent an over-estimate due to insufficient solar exposure and influence from the higher temperature TL peak. Further analysis using optically stimulated luminescence, which is much more easily minimised during the sediment transport phase, may provide the solution to this question. The TL age of $25.6 \pm 3.2 \mathrm{ka}$, determined from the higher temperature plateau region, is more likely to represent the previous emplacement event in that the stored TL energy is more stably preserved at this higher energy end of the TL spectrum. It is of interest to note that ages of around $25 \mathrm{ka}$, when sea levels were 130 metres lower than at present, are frequently encountered in marine sedimentary deposits along the NSW south coast. These have been interpreted, at eight locations, as representing transport of relict sediment from the continental shelf to the coast by tsunami (Bryant et al., 1996).

\section{Bellambi Beach}

Bellambi Beach is situated to the north of Wollongong (Fig. 1) and represents, according to Young et al. (1995), the best example of anomolous deposition of the eight sites reported. Here a 1.0-1.2 metre humate beach sand containing isolated boulders lies on top of a Holocene estuarine clay. These two units are overlain with a Holocene beach sand. The radiocarbon age of the lower estuarine clay is reported as $6.6 \pm 0.08 \mathrm{ka}$ (Beta-43951) and the humate layer between $22.0 \mathrm{ka}$ and $25.6 \mathrm{ka}$ using TL (W1213, W1295-W1297). The Holocene sand yielded a TL age of $7.4 \pm 0.8 \mathrm{ka}$ (W1214). Thus the apparently Pleistocene age humate layer is sandwiched between two Holocene units.

The TL age of the humate layer, determined from the more stable higher temperature portion of the TL spectra, would seem to be correct in that it agrees with the result of a $\mathrm{TL}$ fine grain age analysis performed on a piece of pumice taken from a $20-30 \mathrm{~cm}$ layer immediately on top of the humate nearby. The pumice age of $25.2 \pm 6.2 \mathrm{ka}$ (W1402) represents the time of the eruption during which it was formed. Following this event pumice is known to raft for a briel time only before being deposited in this case in the c. $25 \mathrm{ka}$ sand body which subsequently was to be deposited during a tsunami event. Thus the age of the pumice represents quite closely the timing of the previous deposition of the underlying sediment (Young et al., 1995). It should be appreciated that this determination is from a heated sample which has been completely zeroed of any previously acquired TL signal unlike the sedimentary deposits which may, or may not, have received sufficient solar exposure for TL minimisation to have taken place. Details of this dating procedure are given by Aitken (1985). The age of the underlying estuarine clay unit and the humate layer are essentially confirmed by TL elsewhere along the coastline (see Kioloa section).
The TL temperature plateau characteristics exhibited by the humate samples taken from Bellambi are far from satisfactory in that each is either stepped or sloping towards the high temperature region. suggestive of only a brief solar exposure before deposition (Fig 3). The TL ages determined for this unit therefore would appear to represent the time of the previous depasition rather than that of the tsunami event. This is confrmed by the age determined from the pumice deposited on top of the humate layer. Each of the five sand samples taken from the Bellambi site displayed similar second glow TL characteristics. This suggests that these sands are sourced from an area having the same, or at least similar. mineralogy.

The TL temperature plateau characteristic plot of the overlying Holocene beach sand at Bellambi Beach (W1214) also indicates that there has been insufficient solar exposure to reset the high temperature TL (Fig. 3). The TL age indicated $(7.4 \pm 0.8 \mathrm{ka})$ should therefore be regarded as a maximum value as it is almost certainly influenced by the higher temperature TL levels.

\section{Kioloa Beach}

The TL temperature plateau characteristics and ages determined for samples removed from Bellambi Beach are repeated further along the coastline at Kioloa Beach (Fig. 1) as is discussed by Young et al., (1995). Here a Pleistocene age humate layer formed from reworked sand overlies Holocene clay unit of estuarine origin and in this instance the two are topped with a beach sand of apparent Pleistocene age. The age of the lower clay unit

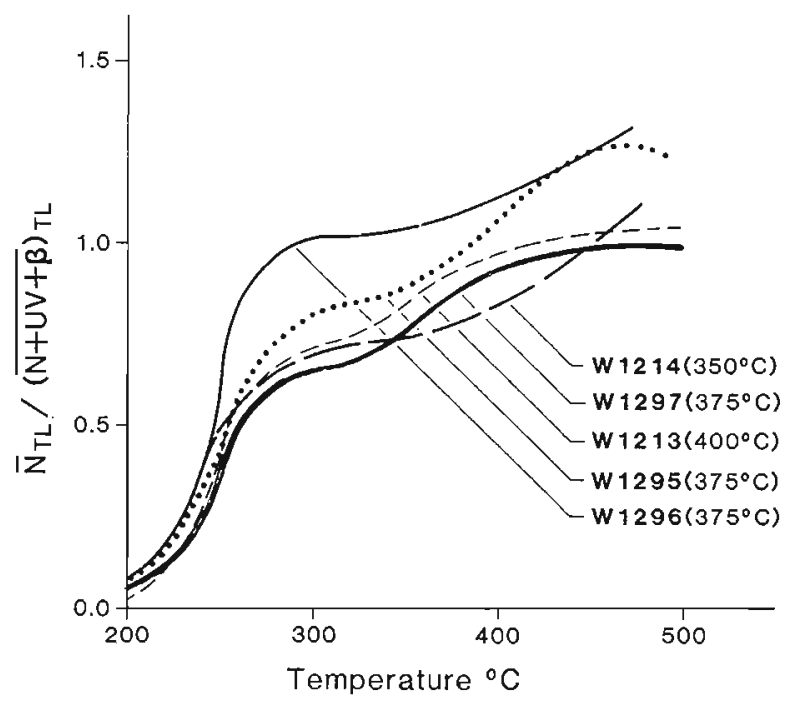

Fig. 3. Bellambi Beach. Curves showing the ratio of natural TL (N) ${ }_{\mathrm{TL}}$ divided by laboratory induced $\urcorner \mathcal{L}(\mathrm{N}+\mathrm{UV}+\mathrm{B})_{\mathrm{TL}}$ with temperature. Plateau regions and analysis temperatures are shown for tsunami overwash samples (W1213, W1295, W1296, W1297) and Holocene beach sand ( $\mathrm{W} \mid 214$ ) 
was determined by TL to be $8.7 \pm 1.7 \mathrm{ka}$ (W1664) and that of the humate layer as $25.4 \pm 3.9 \mathrm{ka}$ (W1642). These ages are in agreement with the ages determined for similar units at Bellambi Beach. In this instance, however, the TL age of the uppermost sand unit is $18.9 \pm 2.8 \mathrm{ka}$ (W1663). Thus, once again a deposit of apparent Pleistocene age overlies a unit deposited during Holocene times.

Here the TL temperature plateau comparison for the humate tsunami deposit (W1642) is strongly suggestive of insufficient exposure before deposition to effect TL resetting (Fig. 4a). The lower estuarine clay (W1664) exhibits a more satisfactory temperature plateau (Fig. 4a) while that of the upper sand unit (W1663) differs in that it rises towards the low temperature end of the plateau comparison (Fig. 4a). The second glow characteristic displayed by the uppermost beach sand differs markedly from that exhibited by the two lower units. The second glow TL spectra exhibited by both the humate sand and the estuarine clay samples are dominated by a strong $325^{\circ} \mathrm{C}$ TL peak, whereas there is only a suggestion of this in the
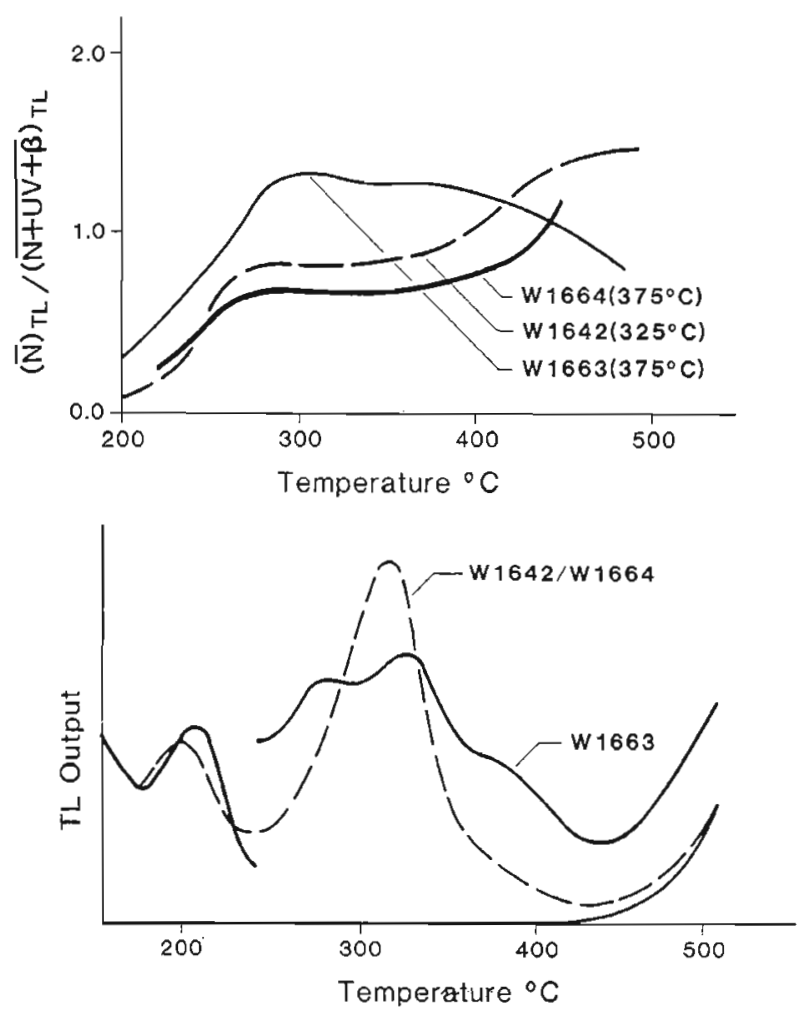

Fig. 4. Kioloa Beach. (a) Curves showing the ratio of natural TL (N) $\mathrm{TL}$ divided by laboratory induced $\mathrm{TL}(\mathrm{N}+\mathrm{UV}+\mathrm{B})_{\mathrm{Tl}}$, with temperature. Plateau regions and analysis temperature are shown for estuarine clay sample (W1664), beach sand (W1663) and humate sand (W1642). (b) Second TL glowcurves demonstrating the characteristics difference between 90-125 micrometre quartz grains separating the upper sand (W1663) and the two underlying units, (W1664) estuarine clay and (W1642) the humate sand. This demonstrates the change in the sedimentary source, or a mixture of sands, of differing provenance. case of the upper sand (Fig. 4b). This coupled with a reverse slope temperature plateau character which slopes towards the low temperature end, rather than the high temperature end of the characteristic, is suggestive of a mix of sand which may well have a different origin.

\section{Atcheson Rock}

Two sand samples (W1782 and W1783) taken from Atcheson Rock south of Bass Point (Fig. 1), attributed to tsunami wave action by Bryant et al. (1996). These exhibit temperature plateau comparative plots which are suggestive of incomplete TL minimisation before deposition (Fig. 5). Sample W1783 exhibits a stepped plateau characteristic as does W1782 although to a lesser degree. The TL age of these samples was determined as $2.3 \pm 0.4 \mathrm{ka}$ and $4.3 \pm 0.6 \mathrm{ka}$ respectively. These values should not be taken as being indicative of the timing of the tsunami event but as maximum depositional age. Thus it would seem that such an event has occurred within the last $2.3 \pm 0.4 \mathrm{ka}$ at this site.

\section{Mointeach Mhor (Scotland)}

A sample taken from a sedimentary sequence described by Shennan and Innes (1994) and identified,

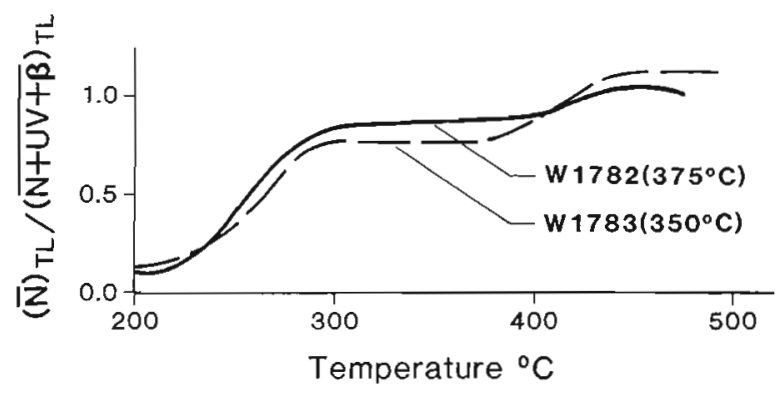

Fig. 5. Atchesons Rock. Curves showing the ratio of natural TL $(N)_{T L}$ divided by laboratory induced TL $(\mathrm{N}+\mathrm{UV}+\mathrm{B})_{\mathrm{TL}}$ with temperature. Temperature plateau regions and analysis temperatures are shown for tsunami overwash samples (W/782 and W1783).

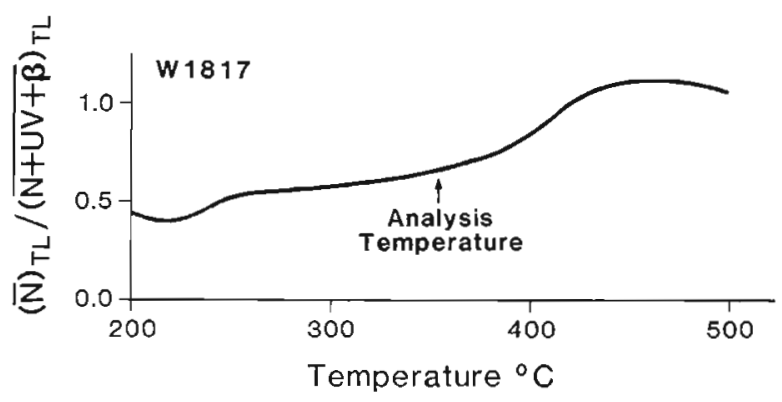

Fig. 6. Mointeach Mhor (Northeast Scotland). Curves showing the ratio of natural TL $(N)_{T I}$, divided by laboratory induced $\mathrm{TL}$ $(\mathrm{N}+\mathrm{UV}+\mathrm{B})_{\mathrm{TL}}$ with temperature. Note the stepped nature of the characteristic. 
Table 1

Data used in the determination of thermoluminescence ages

\begin{tabular}{|c|c|c|c|c|c|c|c|}
\hline Sample no. & $\begin{array}{l}\text { Depositional } \\
\text { environment }\end{array}$ & $\begin{array}{l}\text { Analysis } \\
\text { temperature } \\
\text { ("C) }\end{array}$ & $\begin{array}{l}\text { Palaedose } \\
\text { (grays) }\end{array}$ & $\begin{array}{l}K \\
(\%)\end{array}$ & $\begin{array}{l}\text { Specific activity } \\
(\mathrm{U}+\mathrm{Th}) \\
(\mathrm{Bq} / \mathrm{kg})\end{array}$ & $\begin{array}{l}\text { Annual radiation } \\
\text { flux } \\
\text { (micrograys) }\end{array}$ & $\begin{array}{l}\text { TL age } \\
\text { (ka) }\end{array}$ \\
\hline \multicolumn{8}{|c|}{ Shoalhaven Delta } \\
\hline W1907 & Alluvial & 375 & $>318$ & 1.65 & $65.2 \pm 1.8$ & $2087 \pm 52$ & $>106$ \\
\hline W1908(a) & Tsunami backwash & 325 & $4.3 \pm 4.4$ & 0.8 & $108 \pm 3$ & $3043 \pm 62$ & $15.5 \pm 1.5$ \\
\hline W $1908(b)$ & & 375 & $77.0 \pm 9.6$ & 0.8 & $108 \pm 3$ & $3017 \pm 62$ & $25.6 \pm 3.2$ \\
\hline \multicolumn{8}{|c|}{ Bellambi Beach } \\
\hline W 1213 & Tsunami overwash & 400 & $31.0 \pm 3.7$ & 0.63 & $31.5 \pm 4.0$ & $1208 \pm 63$ & $25.6 \pm 3.3$ \\
\hline $\mathrm{W} 1214$ & Holocene beach & 350 & $21.2 \pm 2.4$ & 0.22 & $127 \pm 4.0$ & $2867 \pm 74$ & $7.4 \pm 0.8$ \\
\hline $\mathrm{W} \mid 295$ & Tsunami overwash & 375 & $19.4 \pm 1.6$ & 0.37 & $17.8 \pm 4.0$ & $884 \pm 74$ & $22.0 \pm 2.6$ \\
\hline W1296 & Tsunami overwash & 375 & $24.4 \pm 3.4$ & 0.18 & $40.9 \pm 4.0$ & $1108 \pm 72$ & $22.0 \pm 3.4$ \\
\hline W 1297 & Tsunami overwash & 375 & $17.3 \pm 1.7$ & 0.33 & $13.7 \pm 4.0$ & $752 \pm 73$ & $23.0 \pm 3.2$ \\
\hline W 1402 & Pumice & 350 & $37.3 \pm 9.0$ & 0.65 & $9.3 \pm 0.3$ & $1477 \pm 70$ & $25.2 \pm 6.2$ \\
\hline \multicolumn{8}{|c|}{ Kioloa Beach } \\
\hline W1642 & Tsunami overwash & 325 & $19.6 \pm 2.8$ & 0.10 & $29.8 \pm 0.9$ & $779 \pm 46$ & $25.2 \pm 3.9$ \\
\hline W1663 & Beach sand & 375 & $15.4 \pm 2.1$ & 0.08 & $28.3 \pm 0.9$ & $808 \pm 51$ & $18.9 \pm 2.8$ \\
\hline W 1664 & Estuarine & 375 & $7.0 \pm 0.5$ & 0.10 & $41.5 \pm 1.3$ & $821 \pm 40$ & $8.7 \pm 0.8$ \\
\hline \multicolumn{8}{|c|}{ Atcheson Rock } \\
\hline W1782 & Tsunami overwash & 375 & $3.2 \pm 0.4$ & 0.09 & $24.1 \pm 0.8$ & $742 \pm 51$ & $4.3 \pm 0.6$ \\
\hline W1783 & Tsunami overwash & 350 & $1.5 \pm 0.2$ & 0.11 & $18.2 \pm 0.5$ & $636 \pm 50$ & $2.3 \pm 0.4$ \\
\hline \multicolumn{8}{|c|}{ Mointeach Mhor (Scotland) } \\
\hline W1817 & Tsunami overwash & 325 & $6.1 \pm 0.2$ & 0.29 & $15.3 \pm 0.5$ & $680 \pm 44$ & $9.0 \pm 0.7$ \\
\hline
\end{tabular}

Cosmic contribution to annual radiation flux assumed to be 150 micrograys. Specific activity levels measured by calibrated a!pha counting over a $42 \mathrm{~mm}$ scintillation screen assuming secular equilibrium: $\mathrm{K}$ levels measured by XRF and atomic emission spectroscopy: $\mathrm{Rb}$ contents assumed to be 50 p.p.m except W 1907 and W 1908 where a 100 p.p.m level is assumed: TL determinations performed using the combined additive and regenerative method using the 90-125 micrometre quartz grain size fraction W1402 analysed by means of the additive fine grain method using the 1-8 micrometre polymineral grain size fraction.

using sedimentological methods, by Dawson (pers. comm., 1994) as the result of tsunami activity, yielded a TL age of $9.0 \pm 0.7 \mathrm{ka}$ (W1817). This sample was taken from the middle of a 0.8 metre thick deposit which is sandwiched between two peat layers radiocarbon dated at $2.5 \mathrm{ka}$ and $6.9 \mathrm{ka}$. The TL temperature plateau provides very little confidence of sufficient solar exposure to enable complete TL resetting to have taken place before deposition (Fig. 6) and is strongly suggestive of rapid deposition. Stratigraphic evidence suggests that this deposit is similar to those described by Dawson and Smith (1997) which have been attributed to a tsunami event occurring between $7.3 \mathrm{ka}$ and $7.0 \mathrm{ka}$ (radiocarbon years) ago and is associated with the Second Stoegga Slide. This is thought to be one of the world's largest submarine sediment slides located on the continental slope west of Norway. This well documented tsunami event provides a valuable comparison with the observations of TL characteristics exhibited by similar coastal sediments found along the southern coastline of New South Wales.

\section{Discussion}

Evidence from several sites along the NSW south coastline suggests that a large body of sand, with a group mean TL age of $23.7 \pm 1.3 \mathrm{ka}$, has provided the bulk of the several coastal sand units deposited upon various beaches in this region. Furthermore this sand has been rapidly deposited with insufficient time for the high energy, more difficult to reset TL electrons, within the quartz sand to be completely reset. There appears, however, to have been sufficient solar exposure during these events for the electrons stored at the less robust, rapidly bleached lower temperature TL electron trap energy levels to have been at least partially reset. The mean TL age of $23.7 \pm 1.3 \mathrm{ka}$ determined for the bulk sample is effectively confirmed by the presence of a pumice sample deposited on top of the tsunami unit at Bellambi Beach (W1214) and dated at $25.2 \pm 6.7 \mathrm{ka}$.

In nearly every case discussed, the TL temperature plateau comparisons exhibited by samples suspected of being the result of tsunami activity suggest incomplete 
TL resetting due to insufficient solar exposure before deposition. This characteristic is repeated at several sites along the NSW south coast and at a well-documented site in the far north of Scotland. Additional supporting evidence for the origin of tsunami activity may also be found in the age reversals found at Bellambi Beach and Kioloa where apparently older sediments lie atop younger deposits. In the Shoalhaven Delta there appears to be a gap of around $100 \mathrm{ka}$ between two sediments which lie one above the other suggestive of a sudden stripping process. Further to this there is a distinct difference between the TL signatures exhibited by the quartz grains extracted from these two units. This lends additional support to the notion that these two sedimentary units have differing provenance, or, at least contain a mixture of quartz sands having different origin.

\section{Conclusion}

From the evidence presented, TL can be used as a useful adjunct to conventional sedimentological techniques providing supportive evidence of tsunami activity. Both the TL temperature plateau characteristic and the second TL glowcurve characteristics exhibited may give an indication that such an event has taken place. In certain instances stratigraphic age reversals may also lend further evidence to such activity. The TL ages determined from such analytical exercises should, however, be treated with caution as they may well be influenced by the age of a previous depositional process. The TL acquired before this may not have been completely removed during the-final depositional phase. Optical luminescence dating such as that carried out by Huntley and Claude (1996) may well provide more reliable depositional ages for these sedimentary deposits. This procedure relies upon those electrons which are reset by optical wavelengths rather than by thermal processes as is the case for TL. Neither process will, however, resolve the age of such an event should it take place during darkness. TL samples are relatively easily prepared and do not require long and tedious sequential sedimentological analysis and when used in conjunction with bracketting
TL or radiocarbon sediment ages provide an additional tool in the growing armoury of techniques at the disposal of coastal geomorphologists.

\section{Aknowledgements}

The authors gratefully acknowledge the laboratory assistance of José Abrantes and Peter Butler. Thanks are also due to Richard Miller for the preparation of the figures and to Jacqui Price for preparing the table of results. Finally we would like to convey our appreciation to the referees for their helpful suggestions in the preparation of the final manuscript. This paper is a contribution to IGCP Project 367, Late Quaternary Coastal Records of Rapid Change: Application to Present and Future Conditions.

\section{References}

Aitken, M.J., 1985. Thermoluminescence Dating. Academic Press, London.

Bryant, E.A., Young, R.W., Price, D.M., 1996. Tsunami as a major control on coastal evolution, southeastern Australia. Journal of Coastal Research 12,831-840. IGCP 367 Special Section.

Dawson, S., Smith, D.E., 1997. Holocene relative sea level changes on the margin of a glacio-isostatically uplifted area: an example from northern Caithness, Scotland. The Holocene (in press).

Huntley, D.S., Claude, J.J., 1996. Optical dating of tsunami-laid sands Quaternary Research 46, 127-140.

Price, D.M., 1994. TL signatures of quartz grains of different origin Radiation Measurements 23, 413-417.

Readhead, M.L., 1984. Thermoluminescence dating of some Australian sedimentary deposits. Unpublished Ph.D. thesis, Australian National University, Canberra.

Shennan, I., Innes, J., 1994. Mointeach Mhor. In: Shennan, I. (Ed.), Field Guide 'Late Quaternary Coastal Records of Rapid Change', IGCP Project 367. First International Meeting Symposium and Field Excursion Dunblane and Fort William, Scotland, U.K., 13-20 September 1994, pp. 24-25.

Young, R.W., Bryant, E.A., Price, D.M., 1995. The imprint of tsunami in Quaternary coastal sediments of southeastern Australia. Bulgarian Geophysical Journal 21, 24-32.

Young, R.W., White, K.L., Price, D.M., 1996. Fluvial deposition on the Shoalhaven Deltaic Plain, southern New South Wales. Australian Geographer 27, 215-234. 